\title{
A Restituição do Poder Familiar: da Possibilidade Jurídica ao Procedimento a Ser Adotado
}

\author{
The Restitution of Family Power: From Legal Possibility to the Procedure to be Adopted
}

\author{
Carlos Canuto Machado
}

Unopar, Curso de Direito. PR, Brasil.

E-mail: carloscmachado@outlook.com.br.

\begin{abstract}
Resumo
A família é a base da sociedade e do Estado. De fato, a convivência em família corresponde a um dos mecanismos preparatórios do indivíduo para vida em sociedade. Desse modo, se mostra importante a atuação dos pais na educação de seus filhos almejando esse múnus público, e para isso, a legislação oferta um complexo de deveres-direitos aos pais denominado de poder familiar. Se exercido de forma irregular o poder familiar dos genitores pode ser destituído pela autoridade judiciária. Em que pese alguns juristas e doutrinadores sustentarem que a destituição é irreversível, o princípio do melhor interesse do menor pode ser aplicado em alguns casos para permitir a restituição do poder familiar, desde que tenha ocorrido uma mudança fática na situação que ensejou a destituição e que o menor não tenha sido adotado. Importante frisar que a restituição do poder familiar não fere a coisa julgada, uma vez que se aplica o disposto no Artigo 505, I do CPC. Sugere-se, portanto, uma nova ação, que poderá restituir o poder familiar do (s) genitor (es), se comprovada a alteração dos fatos que ensejaram a destituição e que a medida se mostra mais proveitosa aos interesses do menor. O procedimento contencioso deverá ser empregado nos casos em que o menor está sob a guarda de outra pessoa. Já nos casos em que o menor se encontra na responsabilidade do Estado, o procedimento descrito no Artigo 109 da Lei $6.015 / 73$ se mostra uma alternativa interessante.
\end{abstract}

Palavras-chave: Poder Familiar. Destituição. Restituição. Procedimento.

\begin{abstract}
Family is the groundwork of society and State. In fact, the family coexistence consists to one of the preparatory mechanisms of the person to live in society. Therefore, it's important the parents actions for their children education, targeting at this public function, and for that, law offers a complex of duties-rights to parents which are called 'family power'. If this 'family power' is irregularly exercised by parents, they may be removed by the judicial authority. Although some lawyers and theoretical support that the 'family power' lost is irreversible, the 'principle of the best interest of the minor' may be applied in some cases to allow the return of family power, since that a factual change has happened on that situation that led to the loss of 'family power' and that the child has not been adopted yet. It is important to highlight that the restitution of 'family power' does not reach the res judicata, since the text of 'Article 505, I of the Brazilian Code of Civil Procedure' is applied. Therefore, a new lawsuit is proposed, which may restore the 'family power' of the parents, if the modification of the facts that led to its dismissal is proven, and that the mandate is more beneficial to the minor's interests. The litigation procedure should be applied in cases where the child is under another person's custody. In cases in which the minor is under State's responsibility, the procedure cited in 'Article 109 of Law Act 6.015 of 1973 " is an interesting alternative.
\end{abstract}

Keyworks: 'Family Power'; Loss of 'Family Power'. Restitution of 'Family Power'. Procedur.

\section{Introdução}

O poder familiar exercido pelos pais em relação aos filhos menores de idade pode ser destituído por diversos motivos, conforme preconiza o Código Civil brasileiro, que explicita sua intenção de sempre resguardar o melhor interesse dos menores.

No que se refere ao procedimento de destituição imperioso a observância ao previsto no Estatuto da Criança $e$ do Adolescente que, no entanto, não orienta acerca da possibilidade de os pais destituídos reaverem o poder familiar. A temática se mostra controversa tanto na doutrina quanto na jurisprudência.

Aos que defendem a não possibilidade da reversão, a coisa julgada se mostra como a maior motivação, sob a alegação de que a destituição constitui procedimento irreversível e a análise do exercício do poder familiar já teria sido objeto de decisão definitiva em processo judicial. Já os que defendem a possibilidade da restituição do poder familiar argumentam que o exercício do poder familiar se trata de relação continuada e, por isso, poderia receber novo julgamento diante de modificação do quadro situacional que ensejou a destituição, isso nos termos do artigo 505, inciso I, do Código de Processo Civil.

A presente pesquisa busca verificar qual das duas teses expostas se mostra mais condizente com o ordenamento jurídico brasileiro. Para tanto, foi realizada uma pesquisa de caráter exploratório, com emprego de levantamento bibliográfico acerca dos temas relacionados a problemática, expondo as posições divergentes. Buscou-se, ainda, debater o procedimento a ser empregado em uma eventual restituição 
do poder familiar, utilizando a mesma técnica metodológica supradita.

Deste modo, em primeiro momento, será discorrido brevemente o 'Direito de Família' e o 'Poder Familiar'. Na sequência, aborda-se o tema da 'Destituição do Poder Familiar', expondo a possibilidade da 'Restituição do Poder Familiar', expondo-se, em seguida, acerca do procedimento empregado para restituição do 'Poder Familiar', utilizando posicionamentos existentes na doutrina e na jurisprudência.

\section{Desenvolvimento}

\subsection{Direito de Família}

Segundo a interpretação histórica, a família é instituto anterior ao Estado e ao Direito e pode-se dizer que é a base do qual se originou o próprio Estado, se constituindo como o núcleo fundamental onde repousa toda a organização social. Por isso, a família merece a proteção do Estado, uma vez que se mostra essencial e sagrada (GONÇALVES, 2011). É possível descrever a família como sendo o âmago da sociedade e o lugar onde o indivíduo está inserido de forma mais íntima. O indivíduo se insere na família pelo seu nascimento ou por laços afetivos e nela obtém sua personalidade e caráter (LOCKS, 2012).

Apesar de uma certa vagueza na concepção e conceituação de família, ela pode significar, de forma universal, grupos compostos de pais e filhos ou um grupo cognático ou ainda um grupo de parentes e seus descendentes que vivem em comunhão (NOBRE, 2014).

De todo modo, há uma impossibilidade de apresentar um conceito único e absoluto acerca de família, tendo em vista o caráter multifacetário da mesma, o que já foi reconhecido, também, pelo Instituto Brasileiro de Direito de Família (IBDFAM) na discussão do Projeto de Lei No 2.285/2007, denominado de Estatuto das Famílias (FIGUEIREDO, 2014).

Paulo Nader (2016, p.40), em posição contrária, ressalta que a definição do objeto de estudo é medida imprescindível e, por isso, ele delimita família como sendo:

[...] Uma instituição social, composta por mais de uma pessoa física, que se irmanam no propósito de desenvolver, entre si, a solidariedade nos planos assistencial e da convivência ou simplesmente descendem uma da outra ou de um tronco comum.

Retomando a abordagem histórica, é possível afirmar que o Estado e o Direito derivam da família. Rui Barbosa, em um de seus momentos célebres, pronunciou que "a pátria é a família amplificada". Em outras palavras, o Estado pode ser considerado uma grande família (MORAES, 2014).

O surgimento do Direito da Família teve como escopo auxiliar na manutenção da própria família, permitindo, desta maneira, que o indivíduo exista como cidadão. O Direito de Família ofertou, ao longo da história, várias concepções de família, que se amoldaram e se alinharam aos valores sociais que vigiam à sua época. Deriva dessa mutabilidade a dificuldade em se alinhar um padrão único de família (LOCKS, 2012). Esse padrão multifacetário da família acompanha uma sociedade democratizante, que aceita várias vertentes de família - monoparentais, anaparentais, heterossexuais, homoafeativas, matrimoniais, divórcio grisalho, etc. - em contramão do que se via antes, quando a família se originava, obrigatoriamente, do casamento matrimonial (FIGUEIREDO, 2014).

Atualmente, contudo, o Direito de Família pode ser considerado um sub-ramo do Direito Civil, que dispõe sobre as entidades familiares e recebe forte influência da Constituição Federal, principalmente do é exposto nos artigos 226 ao 230 e, também, do Direito das Coisas e do Direito das Sucessões (NADER, 2016).

Tartuce (2016) destaca que o atual Código Civil divide o Direito de Família em duas grandes vertentes:

Figura 1 - Divisão do Direito de Família

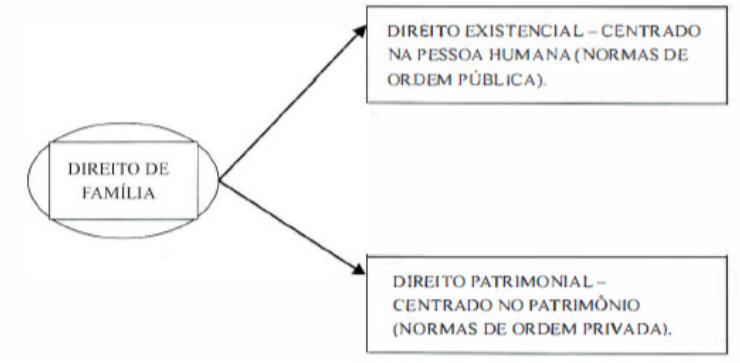

Fonte: Tartuce (2016, p. 1182).

No Código Civil é possível verificar que os artigos 1.511 a 1.638 cuidam do Direito Pessoal ou Existencial, enquanto os artigos 1.639 a 1.732 aborda o Direito Patrimonial do Direito de Família (TARTUCE, 2016). Entretanto, o Direito Civil Brasileiro vem se personificando cada vez mais - ao mesmo tempo em que se despatrimonializa -, observando a tendência constitucional de se priorizar a pessoa, deixando o patrimônio no papel de coadjuvante. Neste contexto, a família também vem sofrendo modificações estruturais e funcionais nos últimos anos, e isso se deve, principalmente, aos princípios - a maioria de ordem constitucional - que amparam o tema (TARTUCE, 2016). Alguns desses princípios, destaca-se a seguir:

- Princípio da proteção da dignidade da pessoa humana: de difícil definição, este princípio está relacionado à realidade do indivíduo em seu contexto social, analisado em uma ótica particular. Sua previsão é de ordem constitucional e se encontra enunciada logo no artigo primeiro, inciso terceiro, o que impõe a ele o grau de princípio máximo ou superprincípio. No Código de Processo Civil está replicado no artigo $8^{\circ}$, que profere: "Ao aplicar o ordenamento jurídico, o juiz atenderá aos fins sociais e às exigências do bem comum, resguardando e promovendo a dignidade da pessoa humana [...]". O princípio da dignidade da pessoa humana está intimamente relacionado ao Direito de Família e se verifica sua aplicação em muitos casos, como, por exemplo, no abandono afetivo de um dos genitores em relação ao filho.

- Princípio da Solidariedade Familiar: a solidariedade está prevista no artigo $3^{\circ}$, I da Constituição Federal e pode ser entendida como "responder pelo outro" ou "preocupar-se 
com a outra pessoa". O Direito de Família maximiza este sentido ao direcioná-lo para um caráter afetivo, social, moral, patrimonial, espiritual e sexual.

- Princípio da Igualdade entre os Filhos: extraído do artigo $227, \S 6^{\circ}$ da Constituição Federal, este princípio coloca em pé de igualdade de direitos e qualificações os filhos havidos no casamento ou fora dele e os adotivos. Também estão inseridos nesta igualdade os filhos obtidos por inseminação artificial heteróloga e os afetivos (artigo 1.593, do Código Civil).

- Princípio da Igualdade entre Cônjuges e Companheiros: de forma análoga à igualdade dos filhos, a Constituição Federal, em seu artigo 226, § 5 , e o Código Civil, em seu artigo 1.511, trouxeram equivalência entre homem e mulher na relação matrimonial. Esse princípio é bastante importante, pois propicia uma despatriarcalização do Direito de Família, deixando-o mais democrático. Terá influência, também, na transição ocorrida do Pátrio Poder para o Poder Familiar.

- Princípio da não intervenção ou da liberdade: análogo ao princípio da autonomia privada, o princípio da não intervenção confere à unidade familiar liberdade para seu planejamento, desestimulando a intervenção estatal ou de entes privados na relação existente entre os membros da família. Encontra-se firmado em texto legal, no artigo 1.513 do Código Civil e reforçado pelo artigo $1.565, \S 2^{\circ}$.

- Princípio do maior interesse da criança e do adolescente: baseado no artigo 227, caput, da Constituição Federal, nos artigos 1.583 e 1.584 do Código Civil e ainda nos artigos $3^{\circ}$ e $4^{\circ}$ do Estatuto da Criança e do Adolescente, este princípio prioriza, de forma absoluta, os direitos fundamentais da criança e do adolescente, atribuindo ao Estado, à família e à sociedade a responsabilidade pela efetivação desses direitos.

- Princípio do Afeto: mesmo não estando positivado na Constituição Federal, o afeto corresponde, atualmente, ao principal fundamento das relações familiares. É possível atribuir que ele decorre dos princípios da dignidade da pessoa humana e da solidariedade. Este princípio teve aplicabilidade prática no Direito de Família nos últimos anos, principalmente no reconhecimento da união estável de forma análoga ao casamento e, também, na paternidade não biológica, denominada de paternidade socioafetiva.

Aplicam-se ainda ao Direito de Família, os princípios da boa-fé objetiva e da função social, com conceitos a aplicabilidades análogos aos demais ramos do Direito Civil (TARTUCE, 2016).

Trazido os princípios que permeiam o Direito de Família, se faz necessário direcioná-los às relações familiares, esclarecendo a possibilidade da intervenção estatal neste núcleo, nos casos em que crianças e/ou adolescentes estão expostos a situações de vulnerabilidade em decorrência da atuação de seus genitores. Antes, porém, é importante abordar e explorar brevemente a temática do Poder Familiar.

\subsection{Poder Familiar}

Naturalmente, no início de sua vida, todo o ser humano necessita de cuidados desprendidos por outrem para suprir sua criação e educação. Dentro de uma ótica assistencialista, é possível afirmar que o poder familiar possui um caráter assistencialista e estaria baseado na solidariedade familiar (FIGUEIREDO, 2014).

O Poder Familiar pode ser definido como um conjunto de direitos e deveres exercido pelos pais, em igualdade de condições, quanto à pessoa e aos bens de seus filhos menores não emancipados, a fim de que possam desempenhar os encargos que a norma jurídica lhes impõe, em vista do melhor interessa da infância e juventude (FIGUEIREDO, 2014).

Percebe-se que o Poder Familiar não corresponde a um direito subjetivo que pode ser exercido livremente pelos pais, mas sim como uma função de ordem pública que miscigena poder e dever direcionada ao interesse do filho menor de idade. A Constituição Federal, em seus artigos 227 e 229 apontam para essa direção:

Art. 227. É dever da família, da sociedade e do Estado assegurar à criança, ao adolescente e ao jovem, com absoluta prioridade, o direito à vida, à saúde, à alimentação, à educação, ao lazer, à profissionalização, à cultura, à dignidade, ao respeito, à liberdade e à convivência familiar e comunitária, além de colocá-los a salvo de toda forma de negligência, discriminação, exploração, violência, crueldade e opressão.

Art. 229. Os pais têm o dever de assistir, criar e educar os filhos menores, e os filhos maiores têm o dever de ajudar e amparar os pais na velhice, carência ou enfermidade (BRASIL, 1988).

Diniz (2010) aponta alguns caracteres do Poder Familiar: munus público: conforme já exposto, o poder familiar transita entre um direito-função e um poder-dever, se situando num ponto intermediário entre o poder e o direito subjetivo; irrenunciável: pois os pais não podem abrir mão dele.

Antes de continuar com as características elencadas pela civilista Maria Helena Diniz acerca do Poder Familiar, é importante mencionar o disposto no artigo 166 do Estatuto da Criança e do Adolescente, recentemente alterado pela Lei pela Lei No $13.509 / 2017$ :

Art. 166. Se os pais forem falecidos, tiverem sido destituídos ou suspensos do poder familiar, ou houverem aderido expressamente ao pedido de colocação em família substituta, este poderá ser formulado diretamente em cartório, em petição assinada pelos próprios requerentes, dispensada a assistência de advogado.

$\S 1^{\circ} \mathrm{Na}$ hipótese de concordância dos pais, o juiz:

I - na presença do Ministério Público, ouvirá as partes, devidamente assistidas por advogado ou por defensor público, para verificar sua concordância com a adoção, no prazo máximo de 10 (dez) dias, contado da data do protocolo da petição ou da entrega da criança em juízo, tomando por termo as declarações; e

II - declarará a extinção do poder familiar (BRASIL, 1990).

Da leitura do referido dispositivo, extrai-se a possibilidade de renúncia ao Poder Familiar, podendo o (s) genitor (es) que consentir com o pedido de colocação do filho em família substituta comparecer em cartório, a fim de formular pedido conjunto e, após a oitiva de todas as partes, o juiz declarará a extinção do poder familiar, não se exigindo qualquer situação prévia desabonadora ou ensejadora da destituição.

Importante discorrer, todavia, que a Lei 13.509/2017 tornou previsível, na esfera normativa, a "Entrega Legal" programa incentivado pelo Conselho Nacional de Justiça para que gestantes e mães que acabaram de dar à luz entreguem seus filhos ao Poder Judiciário, para que este encaminhe a criança à adoção, quando os pais assim desejam. 
Por óbvio que a referida questão deve ser melhor debatida e enfrentada, considerando ainda o disposto nos artigos 28 , 98 e 148 do mesmo códex e ainda, o princípio do melhor interesse do menor. Figueiredo (2014), contudo, sustenta que a redação anterior do referido artigo já trazia a ideia de renúncia do poder familiar. A novação proporcionada pela Lei $\mathrm{N}^{\circ}$ 13.504/2017 implicaria em uma forma mais direta e concisa dessa renúncia. A intenção do legislador deve ser analisada para se buscar a real finalidade da mudança no dispositivo.

Retomando os caracteres do poder familiar expostos por Diniz (2010), podem ser:

- Inalienável ou indisponível, uma vez que os pais não podem dispor a outrem o poder familiar, seja de modo gratuito ou oneroso - cabem aqui as mesmas ponderações já apresentadas acima acerca da irrenunciabilidade.

- Imprescritíveis: os genitores não perdem o poder familiar por deixar de exercê-lo. Somente finda ou cessa o poder familiar nos casos previstos em lei.

- Incompativel com a tutela: nunca um detentor do poder familiar terá a tutela de um menor.

- Autoridade: há um vínculo de subordinação dos filhos em relação aos genitores.

O poder familiar compete aos pais de forma igualitária e, na ausência ou impedimento (por exemplo por incapacidade mental), o outro o exercerá exclusivamente (DINIZ, 2010). As atribuições/obrigações decorrentes do poder familiar estão descritas no artigo 1.694, do Código Civil:

Art. 1.634. Compete a ambos os pais, qualquer que seja a sua situação conjugal, o pleno exercício do poder familiar, que consiste em, quanto aos filhos:

I - dirigir-lhes a criação e a educação

II - exercer a guarda unilateral ou compartilhada nos termos do art. 1.584;

III - conceder-lhes ou negar-lhes consentimento para casarem; IV - conceder-lhes ou negar-lhes consentimento para viajarem ao exterior;

$\mathrm{V}$ - conceder-lhes ou negar-lhes consentimento para mudarem sua residência permanente para outro Município;

VI - nomear-lhes tutor por testamento ou documento autêntico, se o outro dos pais não lhe sobreviver, ou o sobrevivo não puder exercer o poder familiar;

VII - representá-los judicial e extrajudicialmente até os 16 (dezesseis) anos, nos atos da vida civil, e assisti-los, após essa idade, nos atos em que forem partes, suprindo-lhes o consentimento;

VIII - reclamá-los de quem ilegalmente os detenha;

IX - exigir que lhes prestem obediência, respeito e os serviços próprios de sua idade e condição (BRASIL, 2002).

O poder familiar pode ser cessado por fato natural, ato voluntário ou sentença judicial e estão descritos no artigo 1.635 do Código Civil. Os fatos naturais são: morte dos pais ou do filho; e maioridade civil do filho. Já os fatos voluntários estão expostos nos incisos II e IV do artigo anteriormente mencionado; por fim, a extinção do poder familiar por sentença judicial corresponde a destituição do poder familiar, prevista no inciso $\mathrm{V}$ do artigo 1.635 e com as motivações descritas no artigo 1.638 (BRASIL, 2002).

O Código Civil estabeleceu situações em que o poder familiar é suspenso, ou seja, é interrompido de forma transitória pelo fato de os titulares deixarem de cumprir alguns dos requisitos inerentes ao seu exercício. Preconiza o artigo 1.637:

Art. 1.637. Se o pai, ou a mãe, abusar de sua autoridade, faltando aos deveres a eles inerentes ou arruinando os bens dos filhos, cabe ao juiz, requerendo algum parente, ou o Ministério Público, adotar a medida que lhe pareça reclamada pela segurança do menor e seus haveres, até suspendendo o poder familiar, quando convenha.

Parágrafo único. Suspende-se igualmente o exercício do poder familiar ao pai ou à mãe condenados por sentença irrecorrível, em virtude de crime cuja pena exceda a dois anos de prisão (BRASIL, 2002).

A suspensão do poder familiar é uma medida temporária, facultativa e limitada. Coelho (2012) esclarece que a suspensão se mostra temporária, pois o juiz ao decretá-la deve estabelecer um prazo de duração para que ela perdure no tempo; é facultativa, pois verificando a autoridade judicial que outras medidas podem alcançar os objetivos esperados, deve aplica-las em prol da preservação do poder familiar; e é limitada, pois pode atingir apenas um ou alguns dos filhos da prole daqueles que detém o poder familiar.

\subsection{Destituição do Poder Familiar}

A destituição do poder familiar é uma medida bem mais grave do que a suspensão que se opera por sentença judicial toda vez que o juiz se convencer que houve uma das causas que a justificam (DINIZ, 2010). As causas que justificam a destituição do poder familiar estão descritas no artigo 1.638, do Código Civil Brasileiro:

Art. 1.638. Perderá por ato judicial o poder familiar o pai ou a mãe que:

I - castigar imoderadamente o filho;

II - deixar o filho em abandono;

III - praticar atos contrários à moral e aos bons costumes;

IV - incidir, reiteradamente, nas faltas previstas no artigo antecedente.

$\mathrm{V}$ - entregar de forma irregular o filho a terceiros para fins de adoção. (Incluído pela Lei n ${ }^{0} 13.509$, de 2017)

Parágrafo único. Perderá também por ato judicial o poder familiar aquele que: (Incluído pela Lei n ${ }^{\circ} 13.715$, de 2018) I - praticar contra outrem igualmente titular do mesmo poder familiar: (Incluído pela Lei $n^{\circ} 13.715$, de 2018)

a) homicídio, feminicídio ou lesão corporal de natureza grave ou seguida de morte, quando se tratar de crime doloso envolvendo violência doméstica e familiar ou menosprezo ou discriminação à condição de mulher; (Incluído pela Lei ${ }^{\circ}$ 13.715, de 2018)

b) estupro ou outro crime contra a dignidade sexual sujeito à pena de reclusão; (Incluído pela Lei n ${ }^{\circ} 13.715$, de 2018) II - praticar contra filho, filha ou outro descendente: (Incluído pela Lei $\mathrm{n}^{\circ} 13.715$, de 2018)

a) homicídio, feminicídio ou lesão corporal de natureza grave ou seguida de morte, quando se tratar de crime doloso envolvendo violência doméstica e familiar ou menosprezo ou discriminação à condição de mulher; (Incluído pela Lei $\mathrm{n}^{\circ}$ 13.715, de 2018)

b) estupro, estupro de vulnerável ou outro crime contra a dignidade sexual sujeito à pena de reclusão. (Incluído pela Lei ${ }^{\circ} 13.715$, de 2018)

Além das condições elucidadas no Código Civil, a 
Consolidação das Leis Trabalhistas, em seu artigo 437, parágrafo único, também prevê como possível a destituição dos pais que permitem que seus filhos trabalhem em locais nocivos à sua saúde ou ao exercício de atividades atentatórias à sua moral (GONÇALVES, 2012).

A destituição do poder familiar é medida permanente, imperativa e ampla. A medida se mostra permanente, pois o juiz não define o tempo em que a medida perdurará no tempo; se mostra imperativa, uma vez que a autoridade judiciária verificando uma das situações que justificam a imposição da medida, deverá aplica-la; e, por fim, é ampla, tendo em vista que atingirá, necessariamente, toda a prole do pai ou da mãe, ou de ambos (COELHO, 2012).

Entretanto, a modificação dada pela Lei N ${ }^{\circ} 13.509 / 2017$, que introduziu o inciso V no artigo 1.638 do Código Civil trouxe a previsão de destituição do poder familiar ao(s) genitor(es) que entregar(em) o filho de forma irregular para terceiros, para fins de adoção. Surge daí a seguinte indagação: Por ser uma medida ampla, a destituição motivada por este inciso alcançaria, também, eventuais filhos já nascidos da mãe ou do pai ou de ambos? E, no caso de incidência nesta prática, estaria em todos os casos a lei primando pelo princípio do melhor interesse do menor?

A priori, a colocação do inciso $\mathrm{V}$ no rol de hipóteses de destituição do poder familiar parece ter trazido uma certa relativização da abrangência ampla desta medida, pois se mostraria inadequada a destituição do poder familiar em relação a todos os filhos, no caso de os genitores incorrerem na entrega irregular do filho caçula para adoção, por exemplo. Entretanto, Gonçalves (2012) não vislumbra objeção do poder familiar do pai ser destituído em relação à filha a qual tenha cometido abuso sexual e mantido em relação ao filho que, por ventura, tenha um bom relacionamento e esteja aprendendo um ofício, já apontando para situação onde a amplitude da destituição possa ser relativizada.

Conforme preconiza o Estatuto da Criança e do Adolescente, a destituição é medida excepcional e somente deve ser considerada nas situações em que os pais coloquem, por circunstâncias extremas, em risco a dignidade de seus filhos (DUQUE, 2015). Ademais, a medida não corresponde, necessariamente, numa punição dos genitores, mas sim uma proteção aos menores, em que o Estado observa o princípio do melhor interesse do menor e interfere na privacidade da vida familiar para defender os interesses das crianças ou adolescentes. Neste sentido, verifica-se a jurisprudência:

TJ-SC — Apelação Cível AC 00015867920178240019

Concórdia 0001586-79.2017.8.24.0019 (TJ-SC)

Data de publicação: 28/11/2017

Ementa: AÇÃO DE DESTITUIÇÃO DO PODER FAMILIAR. ARTS. 1.635 E 1.638 DO CÓDIGO CIVIL E ARTS. 22 E 24 DO ESTATUTO DA CRIANÇA E DO ADOLESCENTE. SITUAÇÃO DE RISCO, NEGLIGÊNCIA A QUE SUBMETIDA A PROLE. CONVÍVIO DANOSO. RECURSO DESPROVIDO. A destituição do poder familiar, um dos primados básicos que embasam a teoria da proteção integral prevista no Estatuto da Criança e do Adolescente, não se destina a penalizar o genitor negligente, mas sim salvaguardar os interesses da criança e do adolescente no que diz respeito ao desenvolvimento físico, mental, moral, espiritual e social, dignos de pessoa em formação (grifo nosso).

O artigo 23 do Estatuto da Criança e do Adolescente preconiza, ainda, que a carência ou a falta de recursos materiais não podem configurar motivação única para destituição ou suspensão do poder familiar, devendo o Estado, através de programais sociais, realizar a proteção necessária do menor em situação de vulnerabilidade (GONÇALVES, 2012).

O procedimento para destituição do poder familiar está descrito nos artigos 155 e 163 do Estatuto da Criança e do Adolescente e deve observar o direito ao contraditório nos termos do artigo 24 do mesmo códex. A legitimidade ativa do processo de destituição do poder familiar recai sobre: a) o outro cônjuge; b) algum familiar do menor; c) o próprio menor, se púbere; d) a pessoa a quem confiou a guarda; e) e o Ministério Público (DINIZ, 2010).

A petição inicial deverá conter a autoridade judiciária a quem se dirige o pedido, a qualificação da parte autora - sendo o Ministério Público, não se faz necessária - e da parte ré, a exposição dos fatos e dos pedidos e as provas que pretende produzir. Recebida a inicial, o juiz determinará a citação pessoal do réu para oferecer resposta no prazo de dez dias, apresentando as provas que pretende produzir, arrolando testemunhas e juntando documentos. Não tendo condições de constituir advogado, o réu poderá requisitar em cartório e ser-lhe-á nomeado dativo. O magistrado poderá determinar de ofício ou à requerimento a realização de estudo social ou de perícia por equipe multiprofissional.

Apresentada a resposta pelo réu e não sendo o Ministério Público autor da ação, este terá vistas dos autos pelo prazo de cinco dias. Na sequência será designada audiência de instrução, em que serão ouvidos os genitores, caso estejam em local conhecido, as testemunhas e o parecer técnico, se não tiver sido apresentado por escrito. Ainda na audiência, o requerente, o requerido e o Ministério Público poderão se manifestar pelo prazo de vinte minutos cada um - podendo ser prorrogado por mais dez minutos. Na sequência, o juiz poderá prolatar a sentença ainda na audiência, ou adiar, em casos excepcionais, desde que não exceda cinco dias. O procedimento total do processo de destituição do poder familiar não poderá exceder cento e vinte dias corridos (DINIZ, 2010).

Da sentença, caberá recurso de apelação, que deverá ser interposto no prazo de dez dias. O recurso será recebido no efeito devolutivo, conforme dispõe o artigo 199-B do ECA.

\subsection{Restituição do Poder Familiar: Possibilidade Jurídica}

Conforme já mencionado, a destituição se mostra como medida permanente, no sentido de que, o magistrado ao decretá-la, não estabelece um parâmetro de tempo em que a medida se estenderá. Contudo, a lei é silente quanto à possibilidade ou não de sua reversibilidade. Assim, a 
construção da possibilidade jurídica desse pedido remete, necessariamente, a desconstituição da coisa julgada material ao processo de destituição.

É fato que a segurança jurídica, segundo o texto constitucional, está pautada no ato jurídico, no direito adquirido e na coisa julgada (LEITE, 2015). O Código de Processo Civil dispõe em seu artigo 502 que:

Art. 502. Denomina-se coisa julgada material a autoridade que torna imutável e indiscutível a decisão de mérito não mais sujeita a recurso (BRASIL, 2015).

Importante mencionar que a coisa julgada não se confunde com o trânsito em julgado da sentença. Este último ocorre quando não se cabe mais recurso contra a sentença, seja por uma questão temporal, seja por uma questão processual/ recursal.

Ocorrendo o trânsito em julgado inaugura-se a coisa julgada e a sentença passa a ser imutável, seja em seus efeitos materiais, seja em seus efeitos formais (BARROSO, 2010). É nesse sentido que, havendo novo pedido contendo a mesma causa de pedir, o mesmo pedido e as mesmas partes, o julgador deverá analisar o pedido e extinguir a nova ação, nos termos do artigo 485, V do Código de Processo Civil: “Art. 485. O juiz não resolverá o mérito quando: [...] reconhecer a existência de perempção, de litispendência ou de coisa julgada" (BRASIL, 2015). Nesse sentido, por este motivo, a jurisprudência já rejeitou o pedido de restituição do poder familiar:

TJ-SC - Apelação Cível AC 552163 SC 2011.055216-3 (TJ$\mathrm{SC})$

Data de publicação: 29/11/2011

Ementa: APELAÇÃO CÍVEL. AÇÃO DE RESTITUIÇÃO DE PODER FAMILIAR COM PEDIDO DE GUARDA. IMPOSSIBILIDADE. MATÉRIA JÁ ANALISADA EM OUTRA DEMANDA DE DESTITUIÇÃO DE PODER FAMILIAR. COM AMPLA PRODUÇÃO DE PROVAS. GENITOR QUE NÃO POSSUE CONDIÇÕES EMOCIONAIS DE PROPORCIONAR UM AMBIENTE HARMONIOSO PARA EDUCAR SEUS DOIS FILHOS MENORES. COISA JULGADA. EXTINÇÃO DA DEMANDA SEM RESOLUÇÃO DO MÉRITO. EXEGESE DO ART. 267, INCISO V, DO CÓDIGO DE PROCESSO CIVIL. RECURSO CONHECIDO E DESPROVIDO.

Entretanto, é notório verificar os limites da coisa julgada. Barroso (2010) cita a possibilidade de a sentença ser revista quando o seu objeto advir de relação jurídica continuativa e sobrevier modificação no estado de fato ou de direito utilizado pelo julgador na anterior decisão. Ou seja, os casos de julgamento rebus sic stantibus ${ }^{l}$, comportando a anterior sentença alteração por nova ação, ajuizada perante o juiz de primeiro grau.

Não se trata, portanto, de exceção a coisa julgada, mas sim de nova ação que irá considerar novos fatos e questões de direitos distintas daquelas analisadas pela primeira sentença, proferida com base em elementos fáticos não mais existentes. Esta possibilidade jurídica tem previsão legal no artigo 505 do

\section{Código de Processo Civil:}

Art. 505. Nenhum juiz decidirá novamente as questões já decididas relativas à mesma lide, salvo:

I - se, tratando-se de relação jurídica de trato continuado, sobreveio modificação no estado de fato ou de direito, caso em que poderá a parte pedir a revisão do que foi estatuído na sentença. (BRASIL, 2015).

Portanto, o pedido de Restituição do Poder Familiar se mostra possível nestes termos, ou seja, com uma alteração do quadro fático que ensejou a destituição e desde que, atenda os reais interesses do menor, não encontrando ainda objeção na Lei. E, no que tange a objeção na Lei, é preciso elucidar o disposto no artigo $39, \S 1^{\circ}$ do Estatuto da Criança e do Adolescente:

Art. 39. A adoção de criança e de adolescente reger-se-á segundo o disposto nesta Lei.

Parágrafo único. É vedada a adoção por procuração.

$\S 1^{\circ} \mathrm{A}$ adoção é medida excepcional e irrevogável, à qual se deve recorrer apenas quando esgotados os recursos de manutenção da criança ou adolescente na família natural ou extensa, na forma do parágrafo único do art. 25 desta Lei. (BRASIL, 1990)

O dispositivo é bastante claro ao mencionar que a adoção é medida irrevogável e, por isso, não é passível de alteração. Analisando em conjunto com o disposto no artigo 1.635 , IV, que preceitua a extinção do poder familiar com a adoção, é possível concluir que nos casos de destituição do poder familiar seguido à adoção, o pedido de restituição do poder familiar não é possível, pois estaria infringindo norma legal. Tal entendimento se alinha ainda ao melhor interesse do menor, pois não permitiria instabilidades na relação do adotando com os adotantes.

Por outro vértice, analisando dados do Conselho Nacional de Justiça quanto ao perfil de adotantes e de crianças possíveis de adoção no Brasil, verificamos o Quadro 1.

Quadro 1 - Proporção de idades máximas preferidas pelos pretendentes

\begin{tabular}{|c|c|c|c|}
\hline Idade & Proporção (\%) & Idade & Proporção (\%) \\
\hline 0 & 14,78 & 9 & 0,32 \\
\hline 1 & 18,33 & 10 & 0,66 \\
\hline 2 & 19,74 & 11 & 0,15 \\
\hline 3 & 18,79 & 12 & 0,20 \\
\hline 4 & 10,56 & 13 & 0,07 \\
\hline 5 & 9,81 & 14 & 0,05 \\
\hline 6 & 3,62 & 15 & 0,06 \\
\hline 7 & 1,76 & 16 & 0,03 \\
\hline $\mathbf{8}$ & $\mathbf{0 , 9 5}$ & $\mathbf{1 7}$ & $\mathbf{0 , 1 1}$ \\
\hline
\end{tabular}

Fonte: Adaptado de CNJ (2015)

Verifica-se pelo Quadro 1, que a maioria dos postulantes à adoção procuram crianças de até 5 anos de idade para serem adotadas. contudo, o GRÁFICO DA Figura 2, demonstra que essa não é a realidade das crianças que poderão ficar disponíveis para adoção. O Conselho Nacional de Justiça,

1 "Estando assim as coisas". 
analisando as crianças que se encontram institucionalizadas em Casas Abrigos ou Famílias Acolhedoras, cujos pais estão sofrendo processo de Destituição do Poder Familiar e poderiam vir a ficarem disponíveis para adoção, possuem predominância etária entre 1 a 3 anos e 8 a 11 anos.

Figura 2 - Distribuição da faixa etária das crianças institucionalizadas com pais sofrendo o processo de destituição do poder familiar

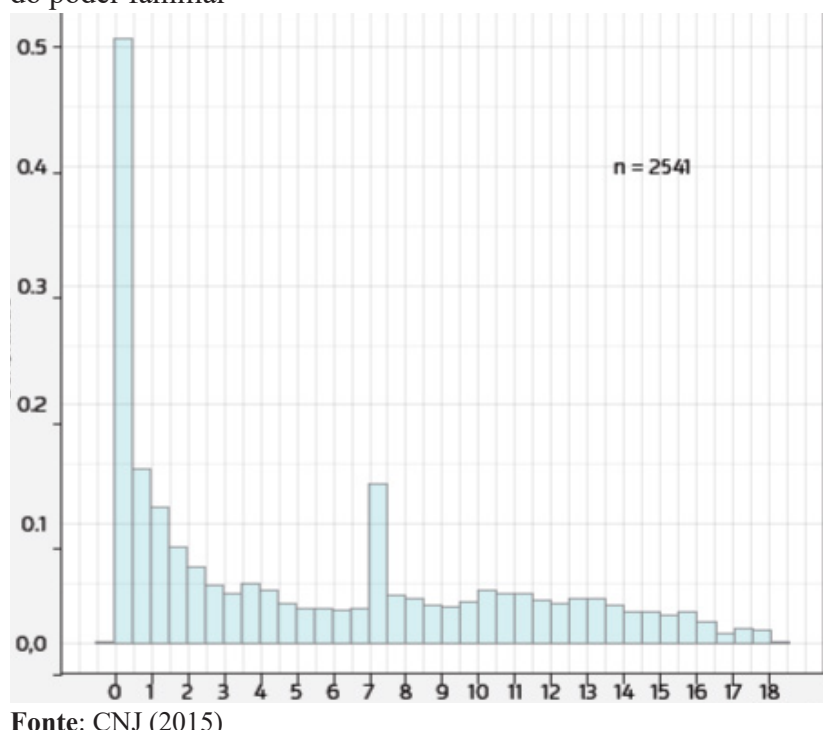

Fonte: CNJ (2015)

A análise dos quadros permite verificar que boa parte das crianças que poderão vir a ser colocadas à disposição para adoção estão em faixa etária destoante da preferência dos pretendentes a adoção. Assim, é possível imaginar que boa parte dessas crianças e adolescentes permanecerão institucionalizados até que atinjam a maioridade civil, sem a oportunidade de conviver em família, o que é um direito constitucional dos menores de idade. Desse modo, a restituição do poder familiar nos casos de reabilitação dos pais, é medida que preserva os direitos constitucionais dos menores.

Ainda é de ressaltar o disposto no artigo 19 do Estatuto da Criança do Adolescente e da Criança:

Art. 19. É direito da criança e do adolescente ser criado e educado no seio de sua família e, excepcionalmente, em família substituta, assegurada a convivência familiar e comunitária, em ambiente que garanta seu desenvolvimento integral.

Veja que o legislador defende a necessidade da criança e do adolescente conviverem em uma família, bem como serem criados neste meio. Assim, a possibilidade da restituição do poder familiar, quando da comprovação da alteração fática que ensejaram o pedido de destituição, se mostra em consonância com as prerrogativas de proteção e melhor interesse do menor e que podem ser encontradas na jurisprudência, a seguir demonstrada:

TJ-SC - Apelação Cível AC 20090153786 SC 2009.015378-6 (Acórdão) (TJ-SC)

Data de publicação: 29/08/2012

Ementa: APELAÇÃO CÍVEL. AÇÃO DE DESTITUIÇÃO

DO PODER FAMILIAR CONTRA AMBOS OS
GENITORES.QUATROFILHOS, SENDOTRÊS MENINOS E UMA MENINA. SENTENÇA DE PROCEDÊNCIA. INSURGÊNCIA RECURSAL DO PAI. MENORES DESABRIGADOS E CONFERIDOS À GUARDA DO IRMÃO MAIS VELHO. POSTERIOR RETORNO DO EXERCÍCIO DA GUARDA DE FATO PELO GENITOR QUANTO AOS TRÊS MENINOS. PERMANÊNCIA DA MENINA COM O IRMÃO PRIMOGÊNITO E A FAMÍLIA DESTE. MENINA BEM INSERIDA NO AMBIENTE FAMILIAR EM QUE SE ENCONTRA. MENINOS IGUALMENTE BEM ASSISTIDOS JUNTO AO GENITOR. CONDUTAS AUTORIZADORAS DA DESTITUIÇÃO DO PODER FAMILIAR ATRIBUÍDAS, PREPONDERANTEMENTE, À MÃE. GENITOR QUE JAMAIS DESISTIU DE RESTITUIR A GUARDA DOS FILHOS. MELHOR INTERESSE DAS CRIANÇAS PRESERVADOS JUNTO AO PAI. MENINA, PORÉM, QUE DEVE TER A GUARDA PROVISÓRIA TORNADA DEFINITIVA NOS AUTOS PRÓPRIOS. SENTENÇA MANTIDA QUANTO À DESTITUIÇÃO DO PODER FAMILIAR MATERNO. RESTITUIÇÃO, CONTUDO, DO PODER FAMILIAR PATERNO. RECURSO CONHECIDO E PROVIDO.

De modo mais pedagógico se mostra a decisão do Tribunal de Justiça do Estado do Rio Grande do Sul que assim menciona e defende:

TJ-RS - Apelação Cível AC 70058335076 RS (TJ-RS)

Data de publicação: 27/05/2014

Ementa: APELAÇÃO CÍVEL. ECA. AÇÃO DE RESTITUIÇÃO DO PODER FAMILIAR. POSSIBILIDADE JURÍDICA DO PEDIDO. PROTEÇÃO INTEGRAL E PRIORITÁRIA DOS DIREITOS DA CRIANÇA E DO ADOLESCENTE. DESCONSTITUIÇÃO DA SENTENÇA EXTINTIVA. 1. A atenta e sistemática leitura dos artigos do Estatuto da Criança e do Adolescente permite concluir que apenas a adoção tem caráter irrevogável, porque expressamente consignado no $\S 1^{\circ}$ do art. 39. Diante do silêncio da lei acerca do restabelecimento do poder familiar, também se pode concluir, a contrário senso, pela possibilidade da reversão da destituição do poder familiar, desde que seja proposta ação própria para tanto, devendo restar comprovada a modificação da situação fática que ensejou o decreto de perda do poder familiar. Desse modo, impõe-se a desconstituição da sentença que extinguiu o processo por impossibilidade jurídica do pedido. 2. À luz da doutrina da proteção integral e prioritária dos direitos da criança e do adolescente preconizada pelo ECA, a intervenção do Estado deve atender prioritariamente aos superiores interesses dos menores, nos termos do art. 100 , inc. II e IV, do ECA, de modo que, caso o retorno dos menores ao convívio materno se mostre a medida que melhor atenda aos seus interesses, não há motivos para que se obste tal retorno, com a restituição do poder familiar pela genitora, mormente porque os menores não foram encaminhados à adoção. 3. Trata-se, no caso, de uma relação jurídica continuativa, sujeita, portanto, à ação do tempo sobre seus integrantes (tal qual ocorre com as relações jurídicas que envolvem o direito a alimentos). Logo, a coisa julgada, formal e material, que antes se tenha produzido, fica preservada desde que as condições objetivas permaneçam as mesmas (cláusula rebus sic stantibus). No entanto, modificadas estas, outra poderá ser a decisão, sem que haja ofensa à coisa julgada. DERAM PROVIMENTO. UNÂNIME.

E, por fim, vale a conclusão trazida por Pasini e Trentin (2015):

[...] Não havendo adoção do infante após a destituição do 
poder familiar e verificado que a família biológica superou as causas que ensejaram a perda da prole e a medida atende os interesses do menor, nada mais justo do que reconduzir o filho aos pais, promovendo o restabelecimento do poder familiar.

\subsection{Procedimento de Restituição do Poder Familiar}

Superada a questão acerca da possibilidade da restituição do poder familiar, resta saber qual o modus operandi para que ela ocorra. A doutrina pouco aborda este tema, uma vez que a própria restituição do poder familiar não é assunto amplamente discutido.

Diniz (2010), ao citar a possibilidade de reversão da destituição do poder familiar prevê apenas que ela se dá por procedimento contencioso, sem elucidar, contudo, quem figuraria no polo ativo e no polo passivo da demanda. De forma análoga à Diniz, Gonçalves (2012) também menciona a restituição do poder familiar, desde que os pais demonstrem que cessaram as condições que impuseram a penalidade, em procedimento contencioso. Coelho (2012) segue a mesma linha ao mencionar que os pais ficam privados de exercer o poder familiar quando deles destituídos, enquanto não comprovarem os motivos que ensejaram a aplicação da medida.

Pela fala dos doutrinadores acima mencionados, verificase que a iniciativa da ação de restituição do poder familiar é dos pais que tiveram esse direito-dever privados, uma vez que incube a eles a comprovação de que os motivos que ensejaram a destituição foram cessados, o que os habilita novamente ao exercício pleno do poder familiar.

Contudo, antes de discutir precisamente o polo ativo e passivo da demanda de restituição do poder familiar, se faz necessário realizar uma breve explanação acerca do uso da ação rescisória: conforme já abordado, a restituição do poder familiar não implica na rescisão da sentença anteriormente proferida, uma vez que não se pretende atingir a coisa julgada material que se formou ali. A pretensão encontra respaldo em tema continuado, em que a situação fática que ensejaram a destituição não mais persistem, buscando assim, a tutela jurisdicional prevista no artigo 505, I do Código de Processo Civil. Assim, é incabível a ação rescisória quando pretendida a restituição do poder familiar em função da alteração da situação fática dos motivos que provocaram a destituição.

Retomando a discussão acerca do procedimento contencioso, a figura do polo passivo não restou demonstrada por nenhum dos doutrinadores estudados. No caso em que exista uma pessoa tutelando pelos direitos do menor, é possível atribuir a ele esse papel. Assim, no primeiro julgado apresentado neste trabalho favorável à restituição do poder familiar, o genitor ingressou com a ação em face do filho mais velho, que detinha a guarda dos irmãos. Contudo, no segundo caso em que o Estado detinha a tutela dos menores, restou firmado no relatório da decisão que a genitora havia ingressado com ação em relação aos filhos, não apontando, contudo, para um polo passivo.

Pasini e Trentin (2015) expõe e defendem a tese apresentada pelo promotor de Justiça Epaminondas da Costa, na qual orienta que o pedido de restituição de poder familiar se trata de um pedido de restauração de registro civil, nos termos do artigo 109 da Lei $N^{\circ}$ 6.015/1973. Sustenta o promotor que, concretizada a Destituição do Poder Familiar ela é averbada no registro de nascimento do menor. Assim, sua reversão poderia seguir o rito descrito no artigo 109, com objetivo de cancelar a referida anotação, como ocorre nas anotações de registros de imóveis, conforme prevê o artigo 295 do mesmo códex. O pedido seria formulado pelo próprio menor, que estaria representado por curador especial, sendo que o Ministério Público atuaria como fiscal da lei e o genitor(es) poderia atuar como eventual interessado. Da Costa afirma ainda a impossibilidade de se instaurar pedido de adoção pelos genitores, uma vez que ela se destina apenas para criar relação de parentesco entre pessoas desvinculadas biologicamente.

De fato, a proposta trazida pelo promotor Epaminondas da Costa se mostra razoável nos casos em que ambos os genitores foram destituídos do poder familiar e que não haja nenhuma pessoa incumbida a resguardar os direitos dos menores, seja na forma de tutela ou de guarda.

O procedimento de adoção se mostra inviável para realizar essa restituição do poder familiar, diante dos ditames legais que norteiam o tema. O Estatuto da Criança e do Adolescente estabelece regras para os pretendes à adoção sejam habilitados e, o Conselho Nacional de Justiça disciplina uma lista de espera para que esses habilitados à adoção tenham a vontade atendida, de modo que a habitação deve ser requerida com a pretensão de adoção e não com a pretensão de se adotar determinada criança/adolescente, sob o risco de incorrer em adoção irregular.

Desde modo, o procedimento adequado para restituição do poder familiar para os casos em que haja uma terceira pessoa tutelando pelos direitos do menor, seria o procedimento contencioso, de preferência o procedimento comum disposto no Código de Processo Civil. Já em casos onde o menor encontra-se institucionalizado, a sugestão dada pelo promotor de Justiça Epaminondas da Costa e defendida por Pasini e Trentin (2015) se mostra satisfatória, sem prejuízo, contudo, que este procedimento seja adotado para todos os casos em que não haja litígio.

\section{Conclusão}

O poder familiar se mostra como um poder-dever que o Direito brasileiro concede aos genitores para que eduquem e criem seus filhos, de maneira a satisfazer as necessidades e ambições dos menores e prepará-los a vida social. Por possuir um caráter público, o poder familiar deve ser acompanhado pelo Estado, devendo intervir quando os genitores se excedem neste direito-dever, a ponto de colocar seus filhos em situação de risco.

Alguns caracteres revestem o poder familiar, como o múnus público, a irrenunciabilidade, inalienabilidade, 
imprescritibilidade, autoridade e incompatibilidade com a tutela. No que tange a irrenunciabilidade, verifica-se que o artigo 166, $\S 1^{\circ}$ do Estatuto da Criança e Adolescente relativiza essa característica, pois permite que, na concordância dos pais, o juiz decrete a destituição do poder familiar. A redação deste parágrafo foi recentemente modificada pela Lei $\mathrm{N}^{\mathrm{o}}$ 13.509/2017, deixando bastante clara a possibilidade da renunciabilidade do poder familiar, em que pese Figueiredo (2014) já vislumbrar essa possibilidade com a redação anterior.

$\mathrm{O}$ poder familiar se extingue por fatos naturais, como a morte dos genitores ou do filho; atos voluntários, como a emancipação do filho; ou sentença judicial [caso da destituição do poder familiar]. O Código Civil Brasileiro enumera em seu artigo 1.638, situações em que o poder familiar pode ser suspenso ou destituído pela autoridade judiciária. As ações de destituição do poder familiar podem ser propostas por um dos genitores em relação ao outro; por algum familiar próximo ao menor; pelo próprio menor [desde que púbere]; ou pelo Ministério Público.

A destituição se mostra como medida permanente, imperativa e ampla. Por permanente não se entende que ela é irreversível, pois, conforme demonstrado, a possibilidade de reversão da destituição do poder familiar se mostra mais proveitoso em alguns casos, atendendo o princípio constitucional de melhor interesse do menor. Por ser ampla, a destituição atende toda a prole e não apenas o filho que esteja em situação de risco. No entanto, Gonçalves (2012) observa a possibilidade dessa amplitude ser desconsiderada no caso do genitor que tenha sido destituído do poder familiar por ter cometido abuso sexual com a filha, porém se mostraria proveitoso continuá-la em relação ao filho, com quem possua relação harmoniosa e proveitosa para o menor.

Cita-se, ainda, a amplitude da medida na hipótese listada no inciso V do artigo 1.638, inserida pela Lei $\mathrm{N}^{\circ} 13.509 / 2017$, em que os genitores serão destituídos do poder familiar se entregarem o filho de forma irregular para adoção.

Como é sabido, existem muitos casos no Brasil em que os pais acabam entregando o último filho para ser criado por terceiros, por não possuírem condições financeiras de criar mais uma criança. A eventual entrega desta criança e a manutenção das outras geraria a destituição de toda a prole, mesmo nos casos que os genitores exercem satisfatoriamente o poder familiar em relação aos outros filhos?

Essa questão necessita ser respondida observando o critério da proporcionalidade da medida e, ainda, o melhor interesse dos outros menores. Em uma visão precoce, parece mais uma possibilidade de relativização da amplitude da destituição do poder familiar.

A medida de destituição do poder familiar visa proteger os menores e não punir os pais. Assim, somente deve ser aplicada em circunstâncias extremas, onde os menores se encontram em situação de risco extremo em função da conduta de seus genitores. Vale ressaltar ainda que a falta de recursos materiais não pode, em hipótese alguma, ser responsável pela aplicação da medida de destituição do poder familiar. O procedimento para destituição do poder familiar encontra-se descrito no Estatuto da Criança e do Adolescente, entre os artigos 155 e 163, e deve perdurar o prazo máximo de cento e vinte dias. Da sentença, caberá recurso, que interverá ser interposto no prazo de dez dias, sendo que este será recebido apenas no efeito devolutivo.

Sendo destituído o poder familiar, o menor deverá ser encaminhado para adoção. Em se realizando a adoção, não há margem para a restituição do poder familiar, em função do disposto no artigo 39, $\S 1^{\circ}$ do Estatuto da Criança e do Adolescente e, ainda, no artigo 1.635, IV do Código Civil. Entretanto, verifica-se que o perfil das crianças e adolescentes existentes nas instituições de acolhimento, na maioria dos casos, não atende às expectativas daqueles que postulam a adoção. Assim, a destituição acaba sendo uma sentença que "condena" o menor a permanecer institucionalizado até que complete a maioridade civil, sem a possibilidade de conviver numa família, conforme preconiza o artigo 19 do Estatuto da Criança e do Adolescente.

Neste sentido, a destituição ao invés de proteger, acabar por desproteger o menor, pois retira dele o direito constitucional de conviver em família. Diante disso, surge a questão acerca da possibilidade de os genitores destituídos poderem restituir o poder familiar. Ao aplicar o princípio do melhor interesse do menor, conclui-se que existe sim essa possibilidade, desde que os genitores comprovem que as situações motivadoras da destituição não mais persistem. E, vale ressaltar que a restituição do poder familiar não fere a coisa julgada, pois corresponde a relação jurídica continuativa, em que a modificação da situação fática gera novos fatos e possibilita um novo julgamento, nos termos do artigo 505, I do Código de Processo Civil.

No que tange ao procedimento para a restituição do poder familiar, verifica-se que procedimento contencioso se mostra mais adequado nas situações em que os menores já se encontram sob a guarda ou tutela de alguma pessoa, enquanto o procedimento previsto no artigo 109 da Lei 6.015/73 se mostra como uma opção interessante quando o menor se encontra institucionalizado.

Por fim, conforme preconiza o artigo 19 do Estatuto da Criança e do Adolescente, a permanência da criança e do adolescente em sua família natural é medida que deve ser buscada e o Estado deve empreender todos os esforços possíveis para concretizá-la, pois corresponde a um direito do próprio menor.

\section{Referências}

BARROSO, C.E.F.M. Teoria geral do processo e processo de conhecimento. São Paulo: Saraiva, 2010.

BRASIL. Constituição Federal de 1988. Disponível em: <www. planalto.gov.br/ccivil_03/constituicao/constituicao.htm>. Acesso em: 20 fev. 2020

BRASIL. Estatuto da Criança e do Adolescente. Lei $\mathrm{N}^{\circ}$ 
8.069/1990. Disponível em: <www.planalto.gov.br/ccivil 03/ Leis/L8069.htm>. Acesso em: 16 mar. 2020.

BRASIL. Código Civil. Lei No 10.406/2002. Disponível em: <www.planalto.gov.br/ccivil_03/LEIS/2002/L10406.htm>. Acesso em: 10 mar. 2020.

BRASIL. Código de Processo Civil. Lei No 13.105/2015. Disponível em: <www.planalto.gov.br/ccivil_03/Ato20152018/2015/Lei/L13105.htm>. Acesso em: 4 abr. 2018.

CNJ - Conselho Nacional de Justiça. Justiça pesquisa: tempo dos processos relacionados à adoção no Brasil - uma análise sobre os impactos da atuação do Poder Judiciário. 2015. Disponível em: <www.cnj.jus.br/files/conteudo/destaques/arquivo/2015/07/ 8aab4515becd037933960ba8e91e1efc.pdf $>$. Acesso em: 20 mar 2020.

COELHO, F.U. Curso de Direito Civil: família e sucessões. São Paulo: Saraiva, 2012.

DINIZ, M.H. Curso de Direito Civil Brasileiro: direito de família v.5. São Paulo: Saraiva, 2010.

DUQUE, L. Formas de intervenção do Estado no âmbito familiar. Disponível em: <https://lcecilia.jusbrasil.com.br/ artigos/237626562/formas-de-intervencao-do-estado-no-ambitofamiliar>. Acesso em: 15 maio 2020.

FIGUEIREDO, L.; FIGUEIREDO, R. Direito Civil: família e sucessões. Salvador: Juspodivm, 2014.

GONÇALVES, C.R. Direito Civil Brasileiro: direito de família.
São Paulo: Saraiva, 2011.

GONÇALVES, C.R. Direito Civil Brasileiro: direito de família. v. 6. São Paulo: Saraiva, 2012.

LEITE, G. Sentença e coisa julgada no Código de Processo Civil de 2015. Disponível em: < https://jus.com.br/artigos/44636/ sentenca-e-coisa-julgada-no-codigo-de-processo-civil-de-2015>. Acesso: 4 jun. 2020.

LOCKS, J.C.A. As novas modalidades de família. Disponível em: $\quad<$ www.boletimjuridico.com.br/doutrina/artigo/2728/asnovas-modalidades-familia $>$. Acesso em: 21 jan. 2020.

MORAES, M.A.V. A evolução do conceito de família no ordenamento jurídico brasileiro. 2014. Disponível em: $<$ https:// jus.com.br/artigos/28568/a-evolucao-do-conceito-de-familia-noordenamento-juridico-brasileiro>. Acesso em: 12 fev. 2020.

NADER, P. Curso de Direito Civil: direito de família. Rio de Janeiro: Forense, 2016.

NOBRE, R.I.R.S. Conceito e evolução do Direito de Família. 2014. Disponível em: $<$ https://jus.com.br/artigos/29977/conceitoe-evolucao-do-direito-de-familia>. Acesso em: 12 fev. 2020.

PASINI, V.C.L.; TRENTIN, F.. Restabelecimento do poder familiar: reintegração à família natural. Interfaces Cient. Direito, v.4, n.1, p. 65-74, 2015.

TARTUCE, F. Manual de Direito Civil. Rio de Janeiro: Forense, 2016. 